\title{
Tendinosis-like changes in denervated rat Achilles tendon
}

\author{
Roine El-Habta ${ }^{1 *}$, Jialin Chen ${ }^{1}$, Jessica Pingel ${ }^{2}$ and Ludvig J. Backman ${ }^{1,3}$
}

\begin{abstract}
Background: Tendon disorders are common and lead to significant disability and pain. Our knowledge of the 'tennis elbow', the 'jumpers knee', and Achilles tendinosis has increased over the years, but changes in denervated tendons is yet to be described in detail. The aim of the present study was to investigate the morphological and biochemical changes in tendon tissue following two weeks of denervation using a unilateral sciatic nerve transection model in rat Achilles tendons.

Methods: Tendons were compared with respect to cell number, nuclear roundness, and fiber structure. The non-denervated contralateral tendon served as a control. Also, the expression of neuromodulators such as substance $P$ and its preferred receptor neurokinin-1 receptor, NK-1R, was evaluated using real-time qRT-PCR.

Results: Our results showed that denervated tendons expressed morphological changes such as hypercellularity; disfigured cells; disorganization of the collagen network; increased production of type III collagen; and increased expression of NK-1R.

Conclusion: Taken together these data provide new insights into the histopathology of denervated tendons showing that denervation causes somewhat similar changes in the Achilles tendon as does tendinosis in rats.
\end{abstract}

Keywords: Collagen, Denervation, Rat, Substance P, Tendinosis

\section{Background}

Tendons are vital for human locomotion because they transmit force from contracting skeletal muscle to the bone [1]. Tendon injuries include overuse injuries (tendinosis) [2] and acute injuries (partial tear or rupture) [3]. Surgical repair of torn tendons or muscle-tendon units are technically very demanding surgeries and the healing process is challenging with a high risk of continued reduced functionality $[4,5]$. One major complication in these injuries is denervation due to an injured nerve [6]. When it comes to denervation of the skeletal muscle, it has been reviewed thoroughly how denervation affects the muscle and creates atrophy, cell death and fat infiltration and consequently muscle weakness $[7,8]$. But when it comes to the effects of denervation on tendon tissue, little is known. This is of interest to clinicians who treat patients with peripheral nerve injuries, as a

\footnotetext{
* Correspondence: roine.el-habta@umu.se

${ }^{1}$ Department of Integrative Medical Biology, Section for Anatomy, Umeå

University, Johan Bures väg 12, 90187 Umeå, Sweden

Full list of author information is available at the end of the article
}

better understanding of denervation and its consequences could prevent the development of tendon pathology and improve the outcome of rehabilitation interventions for these patients.

Denervation is distinguished from immobilization (e.g. inability to move a leg because of a bone fracture) by the fact that in denervation there is a loss of nerve supply to the muscle, whereas in immobilization the nerves are intact. Immobilization studies have shown increases of collagen turnover after immobilization [9]. However, studies measuring the cross-sectional area of the Achilles tendon both after short term (2 weeks) and long term immobilization ( 6 weeks) did not observe changes in the cross-sectional area of the tendon, in contrast to the muscle, which already showed significant atrophy after 2 weeks $[10,11]$. These studies indicate that tendon tissue is more resistant to immobilization than the skeletal muscle is [10, 11]. There is evidence suggesting that denervation causes more severe changes of the tendon than immobilization does. For instance, in adult rats unilateral denervation

C The Author(s). 2018 Open Access This article is distributed under the terms of the Creative Commons Attribution 4.0 International License (http://creativecommons.org/licenses/by/4.0/), which permits unrestricted use, distribution, and reproduction in any medium, provided you give appropriate credit to the original author(s) and the source, provide a link to the Creative Commons license, and indicate if changes were made. The Creative Commons Public Domain Dedication waiver (http://creativecommons.org/publicdomain/zero/1.0/) applies to the data made available in this article, unless otherwise stated. 
caused a significantly increased collagen turnover and a significant loss of collagen (5-14\%) after 3 month of disuse [12]. Furthermore, chemical denervation using Botulinum toxin injections have been shown to reduce the peak passive properties of the muscle tendon unit significantly in mice [13]. However, it is not clear whether denervation causes any morphologically and biochemically changes in denervated healthy tendons.

Nerve supply in the tendon is important for proper tendon function and is also related to the intrinsic healing capacity of tendons, specifically the sensory innervation in relation to tendinosis and the repair of ruptured tendons [14]. Normal and pathological tendons includes, in varying degree, sympathetic (adrenalin), parasympathetic (acetylcholine), and sensory (substance P) nerve fibers, as well as free nerve endings [15]. It is known that there is an extensive sprouting of nerve fibers into the healing tendon, which after completed healing regress from the tendon for the neuromodulators to return to baseline [16]. It is also shown that a healing tendon, completely lacking nerve supply, in the state of denervation, insufficiently heal and that the failure load of the tendon is decreased to $50 \%$ [17].

In the present study, we hypothesized that denervation would change both the morphological and biochemical features of the tendon significantly. In order to investigate our hypothesis we examined rat Achilles tendons two weeks following unilateral sciatic nerve transection. The cell number, nuclear roundness, and fiber structure were analyzed and compared with the contralateral healthy leg. Furthermore, the expression of different neuromodulators, including substance $\mathrm{P}$ and NK-1R, were analyzed.

\section{Methods}

\section{Animals}

Tendon biopsies were collected from six $(n=6) 10$ - to 12-week old female Sprague Dawley rats (Taconic Europe A/S) two weeks after unilateral sciatic nerve transection. The contralateral tendon served as a control. All surgical procedures were performed under isoflurane anesthesia (Attane vet, $1000 \mathrm{mg} / \mathrm{g}$, Oiramal Healthcare, UK). Postoperative animals were given the analgesic Finadyne (Schering-Plough, Denmark, $2.5 \mathrm{mg} / \mathrm{kg}$, s.c.) to minimize suffering. Animals were housed alone with free access to water and food, and were allowed to move freely so that the denervated limb could be loaded. As a consequence of denervation, animals loaded their entire foot instead of only the fore foot. Animals were euthanized by first inducing deep anesthesia using $4 \%$ isoflurane inhalation. When no response to stimuli was detected, the chest cavity was opened to induce pneumothorax in combination with cutting of the aorta to induce exsanguation. The rats were kept under isoflurane anesthesia until heartbeats had not been detected for five minutes. The animal care and experimental procedures were carried out in accordance with the Directive 2010/63/EU of the European Parliament and of the Council on the protection of animals used for scientific purposes. The study was also approved by the Northern Swedish Committee for Ethics in Animal Experiments (No. A186-12).

\section{Sampling and sectioning}

After two weeks of denervation, the Achilles tendon was separated from the gastrocnemius muscle using a sharp razor blade. The cut was made $1-2 \mathrm{~mm}$ from the musculotendinous junction and the calcaneus to ensure no muscle or bone tissue was collected. Each tendon was cut longitudinally into two pieces, one for sectioning and one for real-time qRT-PCR. The tendon piece set aside for sectioning was mounted on thin cardboard in OCT embedding medium (Miles Laboratories) and frozen in propane chilled liquid nitrogen, and then stored at $-80^{\circ} \mathrm{C}$ until further use. Sectioning was performed at $-22^{\circ} \mathrm{C}$ using a cryostat-microtome. Series of $7 \mu \mathrm{m}$ thick sections were collected and mounted on glass slides. The sections were processed for either immunohistochemistry or histological evaluation.

\section{Ex vivo analyses}

Sections stained with hematoxylin-eosin were examined in a light microscope. Three different parameters were studied in the denervated tendon as well as the contralateral tendon: cell number, nuclear roundness, and fiber structure. Each section was given a score from 0 to 3 , where 0 indicated no histological changes compared to normal tendon tissue, and 3 indicated changes commonly seen in tendinosis. This points-based system was adopted from Shen et al. [18] and was used to pinpoint the similarities and differences between the denervated and contralateral tendon.

\section{Cell number}

For cell counting, photographs of hematoxylin-eosin sections were taken at 20x magnification and transferred to a computer for further processing. A grid was placed over each sample and three separate squares were counted, each with a size of $0.01 \mathrm{~mm}^{2}$. A mean value was then calculated, and sections of the denervated and contralateral tendon were compared to each other.

\section{Nuclear roundness}

Using ImageJ (version 1.51, National Institutes of Health, USA) the nuclear length and width was measured, and a ratio of the two was calculated to determine the nuclear 
roundness. The cells were chosen randomly. In total, 100 cells were measured in each group before a mean value was determined.

\section{Fiber structure}

To visualize the collagenous connective tissue fiber arrangement in tendon sections a trichrome stain was performed. Slides were placed in preheated Bouin's Fluid for $60 \mathrm{~min}$ at $60^{\circ} \mathrm{C}$ in a fume hood, followed by a $10 \mathrm{~min}$ cooling period. Slides were then rinsed in tap water until clear, plus once in distilled water, and stained with working Weigert's Iron Hematoxylin for $5 \mathrm{~min}$. After rinsing the slides in running tap water they were stained with the following solutions for 10 min each, with washing steps in-between: Biebrich Scarlet/Acid Fuchsin Solution; Phosphomolybdic/ Phosphotungstic Acid Solution; and Aniline Blue Solution. Lastly, Acetic Acid Solution (1\%) was applied to slides for $3 \mathrm{~min}$, and then dehydrated very quickly in 2 changes of $95 \%$ Alcohol, followed by 2 changes of Absolute Alcohol. Slides were mounted in Pertex (Histolab Products AB, code: 00840). Nuclei was stained in black, organized collagen was shown in red, and disorganized collagen in blue, as previously described [19]. All sections were masked to blind the investigators before the histological evaluation.

\section{Immunohistochemistry}

Sections for immunohistochemistry were fixed in $2 \%$ PFA, washed three times in PBS, and blocked in swine normal serum (1:20) for $15 \mathrm{~min}$. Sections were then incubated with rabbit primary antibodies (type I collagen, 1:80, Abcam, ab34710; type III collagen, 1:100; Abcam, ab7778; and NK-1R, 1:50, Santa Cruz, SC-15323) for $60 \mathrm{~min}$ at $37^{\circ} \mathrm{C}$. Washing and blocking was repeated before the sections were incubated with TRITC-conjugated swine-anti-rabbit secondary antibodies (1:40, Dako, R0156) for $30 \mathrm{~min}$ at $37^{\circ} \mathrm{C}$. After a final washing step the slides were mounted in medium containing DAPI (Vector Laboratories, code: $\mathrm{H}-1200)$. Slides were examined in a Zeiss Axioskop 2 plus microscope equipped with an Olympus DP70 camera.

\section{Real-time qRT-PCR}

A piece of the Achilles tendon was homogenized in QIAzol Lysis Reagent (Qiagen, code: 79306). The homogenization procedure was carried out using a handheld tissue ruptor for a couple of minutes until most of the tissue had dissolved. The homogenate was then placed at the benchtop for $5 \mathrm{~min}$ to promote dissociation of nucleoprotein complexes. Then, chloroform (1:5) was added to the tube and shaken vigorously for approximately $15 \mathrm{~s}$. The homogenate was centrifuged at $18600 \times \mathrm{g}$ at $4{ }^{\circ} \mathrm{C}$ for $15 \mathrm{~min}$, after which the upper aqueous phase was transferred to a new tube. After the addition of 1.5 volumes of $100 \%$ ethanol, total RNA was purified using RNeasy Mini Kit (Qiagen, code: 74106) according to manufacturer's instructions. Reverse transcription was performed using TaqMan Reverse Transcription Reagents (Applied Biosystems, code: 4368813) from $1 \mu \mathrm{g}$ RNA. Real-time qRT-PCR was performed with TaqMan Gene Expression Assay (Applied Biosystems) and ViiA 7 Real-Time PCR System (Applied Biosystems). Probes used included: Collagen I (Rn01463848), Collagen III (Rn01437681), Tac1 (Rn01500392), and Tacr1 (Rn00562004). Thermal-cycling conditions were $50{ }^{\circ} \mathrm{C} 2 \mathrm{~min} ; 95^{\circ} \mathrm{C} 20 \mathrm{~s}$; and 40 cycles of $95^{\circ} \mathrm{C} 1 \mathrm{~s}$, and $60^{\circ} \mathrm{C} 20 \mathrm{~s}$. Data was analyzed with ViiA 7 Software (Applied Biosystems). Expression of the glycolytic enzyme Glyceraldehyde 3-phosphate dehydrogenase (Gapdh) was used as an internal control.

\section{Statistical analysis}

Analyses of ex vivo tissue were from six rats. Results are presented as mean \pm SD. Statistical analysis was made with GraphPad Prism 7 using Student's t-test for paired samples. * indicates $p<0.05$, ** indicates $p<0.01$, *** indicates $p<0.001$. Values of $\mathrm{p}<0.05$ were considered statistically significant.

\section{Results}

Denervated tendons display morphological changes

Frozen sections were prepared and stained with hematoxylin-eosin. As exemplified in Fig. 1a there were clear differences between the two groups, such as an increased number of cells, changes in nuclear roundness, and changes in collagen fiber structure. Each of these parameters was examined in more detail using a histological scoring system ranging from 0 to 3, i.e. from normal to pathological (Fig. 1b). These results confirmed that there are significant, tendinosislike changes in denervated rat Achilles tendons two weeks following sciatic nerve transection.

\section{Significant increase in the number of cells in denervated tendons}

For quantitative purposes, photographs of hematoxylineosin sections, as well as DAPI stains, were taken and the nuclei were counted in a computer where the cells could be marked to avoid double counting. Three representative areas from each section were chosen and a mean value was calculated. Data showed a significant increase in the number of cells in the denervated tendon compared to the contralateral tendon (Fig. 2). 
(A)
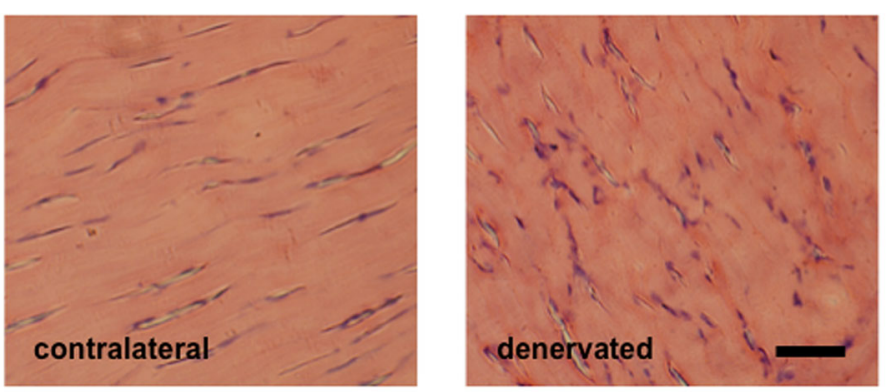

(B)

Histopathological scoring

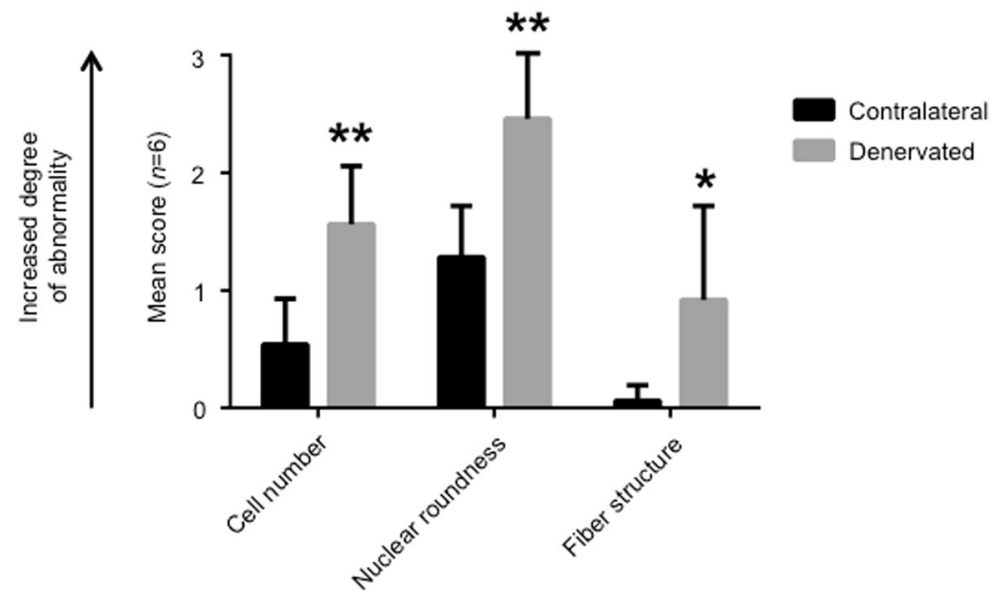

Fig. 1 Histology of denervated rat Achilles tendon. (a) Hematoxylin-eosin staining of the middle part of the Achilles tendon two weeks after unilateral sciatic nerve transection. The rats were allowed to move freely post-surgery. Both sides, i.e. denervated and contralateral, are shown. $\mathrm{Bar}=20 \mu \mathrm{m}$. (b) Histological sections were examined in a light microscope and given a score from 0 to $3(0=$ normal, and $3=$ pathological). All examined parameters were significantly increased in the denervated group compared to the contralateral healthy leg. ${ }^{*}$ indicates $p<0.05$, ${ }^{*}$ indicates $p<0.01$. Values of $p<0.05$ were considered statistically significant

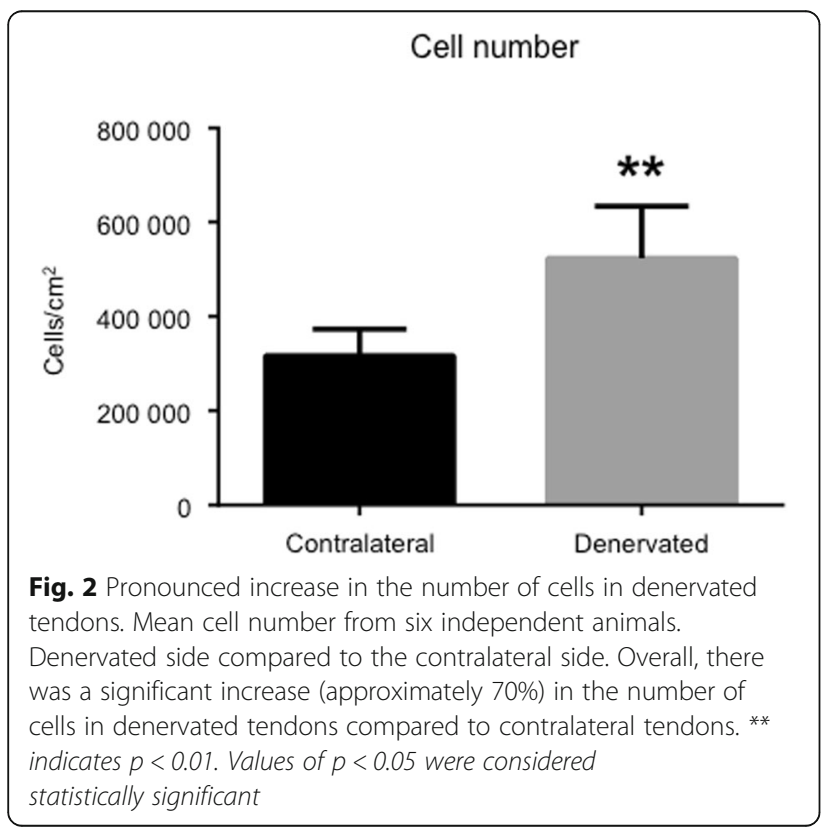

\section{Increased nuclear roundness a common feature of denervated tendons}

One prominent feature of denervated tendon was the nuclear roundness, which could be seen in sections from all six rats (Fig. 3a). Using ImageJ the length and width of each nuclei was measured. Results showed that cells in the denervated tendon had significantly lost their spindle shape and were more round than cells in the contralateral tendon (Fig. 3b).

\section{Disturbed collagen production and organization in denervated tendons}

To evaluate the expression of type I and type III collagen, which is often altered in conditions such as tendinosis, qRT-PCR was performed on tendon biopsies from denervated rats. As shown in Fig. 4a, the expression of both types of collagen was up regulated in denervated samples compared to control samples. The production of collagen was then examined using immunohistochemistry, which confirmed the increased expression on the protein level (Fig. 4b). Additionally, trichrome stain was performed to visualize the collagenous connective tissue 


\section{(A)}
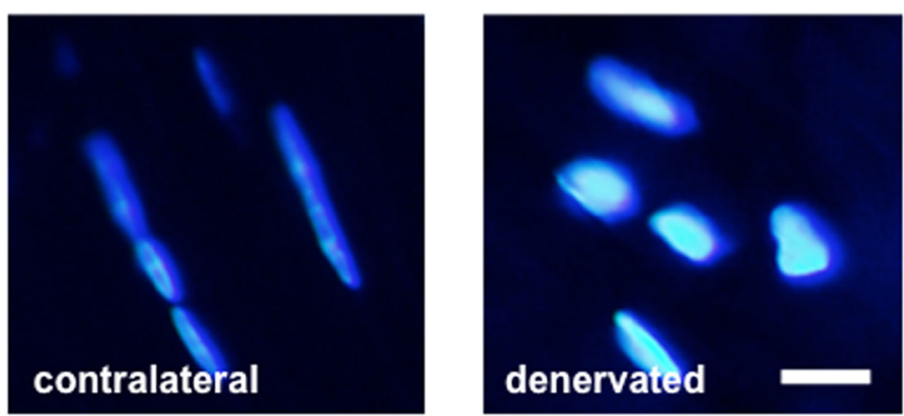

(B)

Nuclear elongation

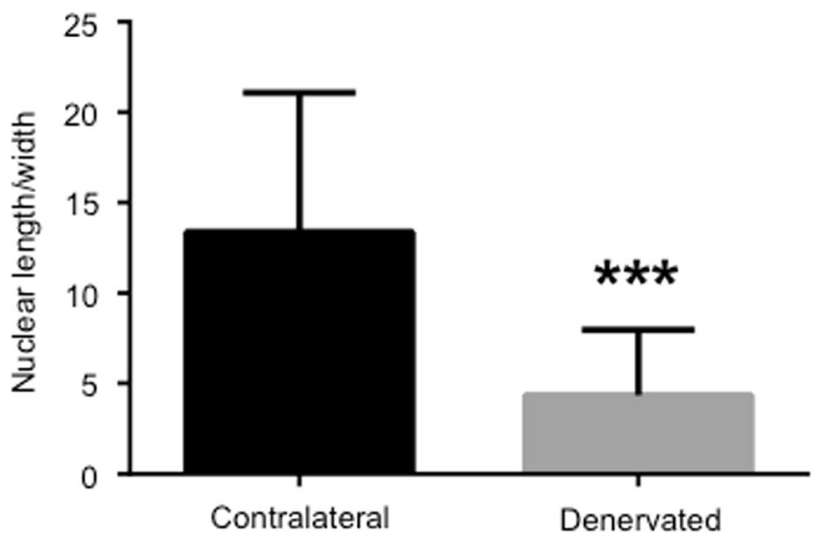

Fig. 3 Increased nuclear roundness in denervated tendons. (a) Nuclei stained with DAPI revealing increased nuclear roundness in denervated samples compared to contralateral samples. Bar $=5 \mu \mathrm{m}$. (b) Ratio between nuclear length and width, measured with ImageJ. The lower the value, the greater the nuclear roundness is. ${ }^{* * *}$ indicates $p<0.001$. Values of $p<0.05$ were considered statistically significant

fibers. As can be seen in Fig. 4c, the dense and parallel structure of the contralateral tendon (red) is missing in the denervated tendon, which has more of a disorganized collagen structure (blue).

\section{Denervated tendons express the neurokinin 1 receptor}

To further investigate the characteristics of denervated tendons and its possible connection to tendinosis, we performed qRT-PCR using markers related to tendinosis such as substance $\mathrm{P}$ and its preferred receptor Neurokinin-1. Results showed that denervated tendons expressed significantly more NK-1R (Tacr 1 ) than contralateral tendons (Fig. 5a). NK-1R was also detected on the protein level in denervated samples, but not in contralateral samples (Fig. 5b). Substance P (Tac1) mRNA expression was also elevated, although not significantly $(p=0.07)$.

\section{Discussion}

Here we present data regarding the histopathology of denervated rat Achilles tendons. For all morphological measures, including cell number, nuclear roundness, and fiber structure, denervated tendons received a significantly higher score than the corresponding contralateral tendon. Additionally, denervated tendons had a significantly higher expression of type I and type III collagen, and NK-1R. These findings indicate that rat Achilles tendons acquired tendinosis-like changes after two weeks of denervation. This is in line with previous observations of increased collagen turnover in tendons after denervation $[9,12]$. In spinal cord injury patients a significant loss of dense connective tissue has been observed 1 year post injury [20] indicating that the increased turnover mainly might be collagen degradation. One important question is whether these changes are a result of neuromuscular changes or are due to immobilization alone. This can be very difficult to disentangle. One previous study observed that 9 weeks of immobilization caused an increased collagen turnover and further the tendon stiffness decreased significantly after immobilization, also indicating a significant loss of dense connective tissue [9].

In skeletal muscle tissue, denervation and immobilization cause significantly different changes [21]. In a study by Ceylan et al. it was observed that loss of muscle volume, weight, and length was significantly lower after denervation than after immobilization [21]. However, these differences 


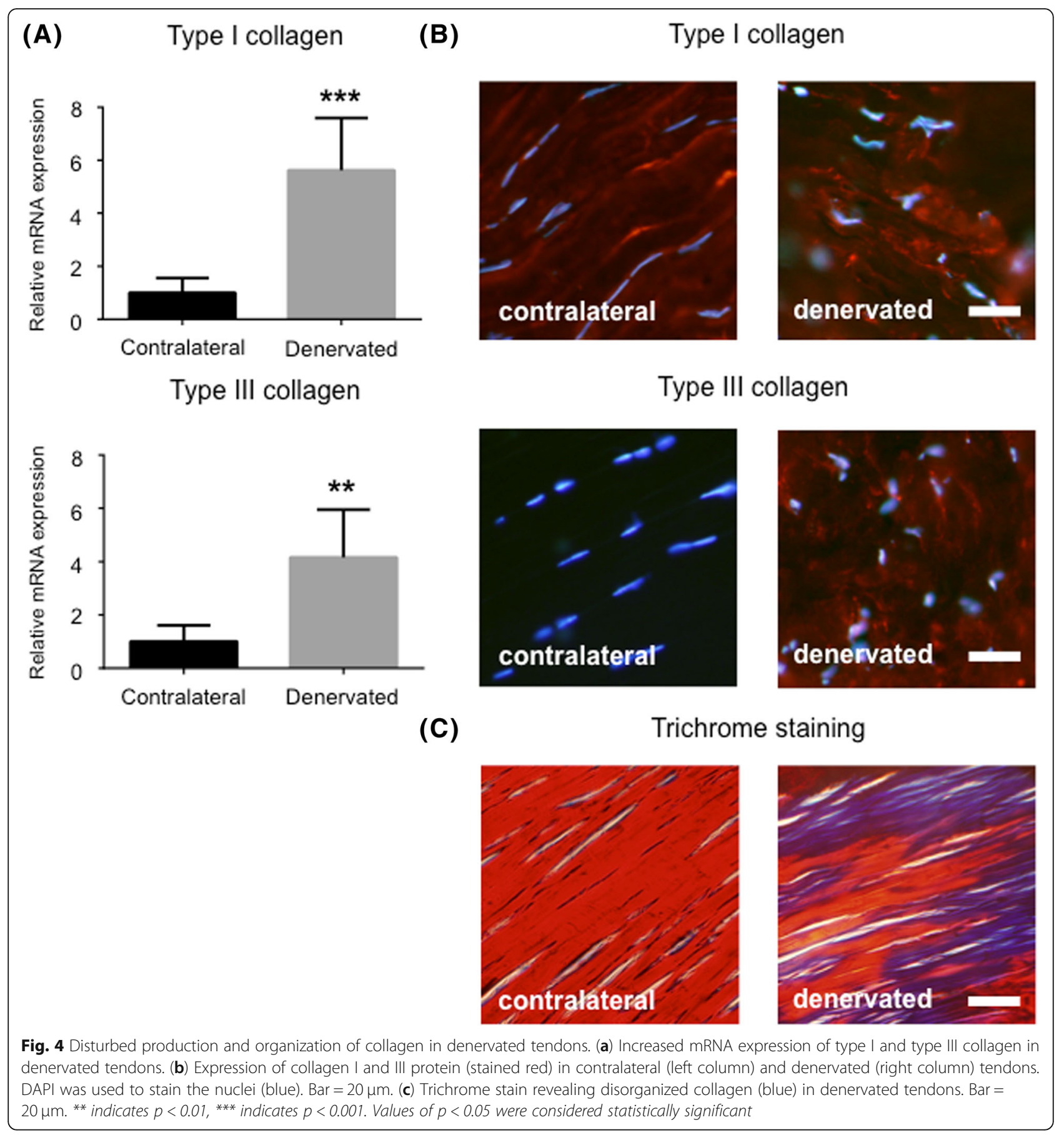

were not seen when the Achilles tendons from the same chicken legs were analyzed after both treatments, only the length of the tendon was significantly lower in the denervated group compared to the immobilized group. This lack of significant difference might be partly explained by the time point chosen for this analysis. Since the tendon tissue changes its properties slower than skeletal muscle, 3 weeks might be too soon to measure significant differences between denervation and immobilization, especially with such rough parameters as volume, weight and length. In the current study we therefore focused on the morphological and biochemical changes of denervated tendons that often precede the macroscopical changes. It should also be noted that in our experiments rats were allowed to move freely post surgery so that the denervated limb could be loaded. Studies have shown that injury of the rat sciatic nerve does not completely compromise locomotion in this animal model [22]. However, because of denervation, the 


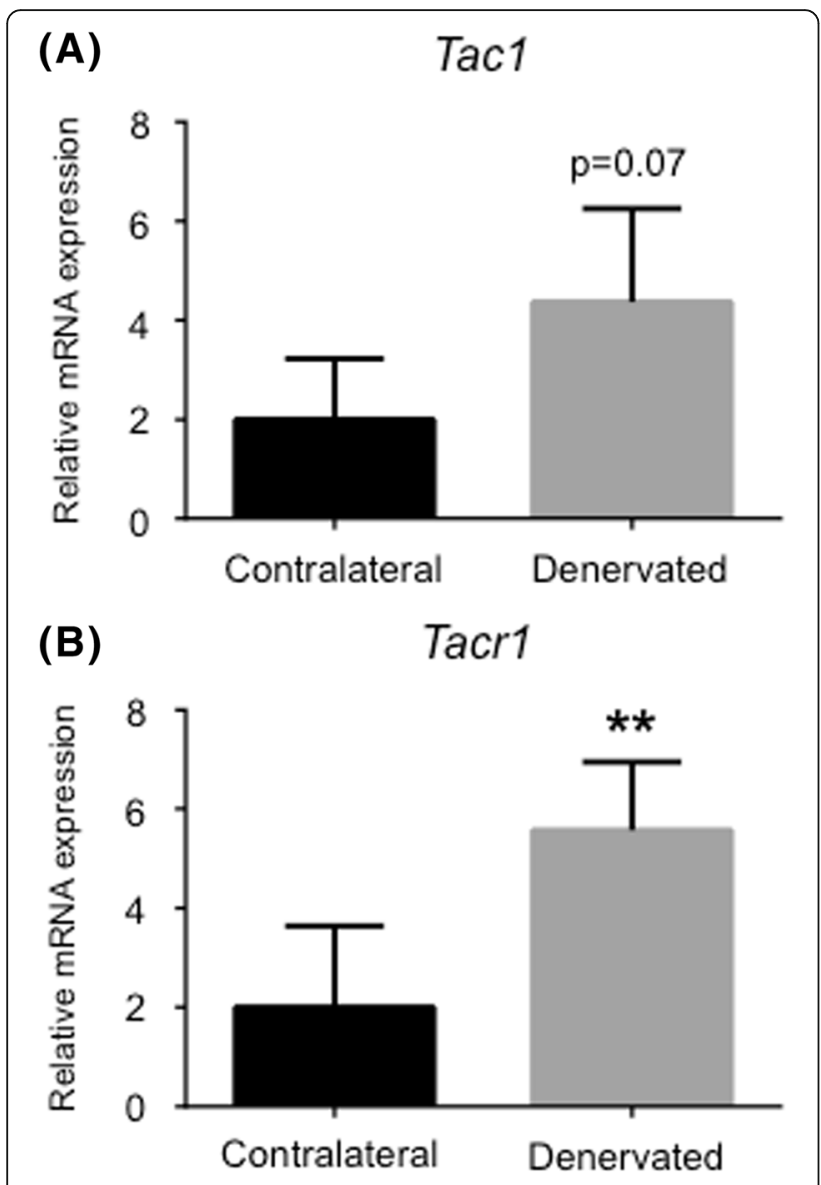

(C)

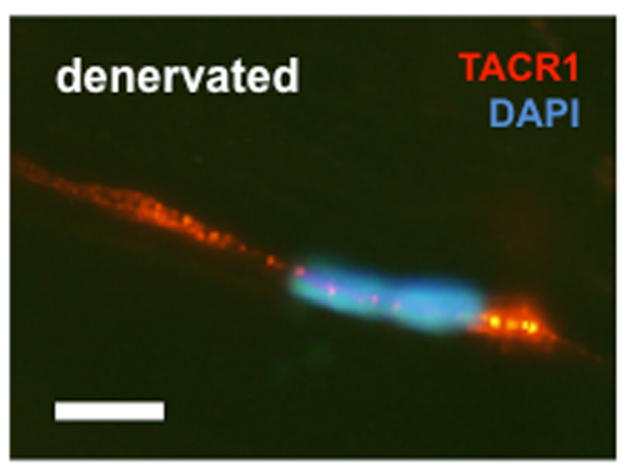

Fig. 5 Denervated tendons express molecules associated with tendinosis. (a) Expression of genes related to tendinosis using qRT-PCR: substance P (Tacl) and its preferred receptor NK-1R (Tacr1). (b) Immunohistochemistry showing positive staining for NK-1R in a denervated tendon. Bar $=5 \mu \mathrm{m}$. ${ }^{*}$ indicates $p<0.01$. Values of $p<0.05$ were considered statistically significant

animals change the way they load both of their feet. As a consequence, one could speculate that the contralateral leg was loaded more post-surgery than pre-surgery. This could potentially lead to changes related to overuse in the contralateral leg.

One of the most prominent features of denervated tendons that were observed in the present study was an increase in the total number of cells (approximately $70 \%$ in denervated samples). This finding might indicate that denervation causes an inflammatory response, and that the increase in cell number might be an inflammatory process that triggers proliferation of tenocytes. However, these cells were not positively stained for CD68 (a macrophage marker) or mast cell tryptase. Exactly what kind of cells that infiltrates the tendon after denervation needs to be investigated further.

Another interesting finding was the difference in nuclear shape between denervated tenocytes and contralateral tenocytes. In denervated tendons the nuclei were generally less elongated, while they remained mostly unaffected in contralateral tendons. We suggest that this might be a consequence of disturbed collagen production and organization. Thus, we examined the expression and production of type I and III collagen using real-time qRT-PCR and immunohistochemistry and observed a significantly increased mRNA expression, as well as protein synthesis, in denervated samples. This was true for both types of collagen. Interestingly, there was no production of type III collagen in the contralateral tendon. The production of type III collagen is usually associated with tendinosis $[23,24]$. Thus the present findings indicate that denervated tendons share some morphological features with tendons that suffer from tendinosis, as well as increased stiffness $[25,26]$. From a clinical perspective this means that patients suffering from muscle atrophy due to neural damage would benefit from a rehabilitation intervention that takes the denervated tendon into account, i.e. treating the tendon as if it were a tendinosis tendon could improve the outcome of rehabilitation intervention and reduce the risk of developing tendon pathology. Type III collagen is also the first collagen type synthesized during the second stage of wound healing (proliferative phase) and is then replaced by type I collagen in the third and final stage (remodeling phase) [27]. The marked production of type I collagen in our denervated tendons could therefore be a sign of a transition from the second phase to the third phase of wound healing.

In the present study, the mRNA expression of NK-1R was significantly increased in denervated samples, and immunoreactions of NK-1R were observed. In a study by Bring et al. the expression of NK-1R was significantly increased in rats that had been mobilized after tendon rupture compared to the immobilized group [28]. The increase was approximately 3 -fold in the mobilized healing group 17 days post-injury. This correlates well with our findings: a nearly 3-fold increase in the mRNA levels for NK-1R at 14 days post sciatic nerve transection. As for the expression of substance $\mathrm{P}$, the mRNA was elevated $(p=0.07)$ but not 
to a significant level. It should however be mentioned that the variation of the substance $\mathrm{P}$ expression was very high between the subjects. While six rats created enough statistical power in order to measure significant differences in all morphological measures, the statistical power was too low to in order to measure statistical differences in substance P. However, it is still tempting to speculate on the importance of substance $\mathrm{P}$ in our case, especially since exogenously administered substance $P$ is known to stimulate early reparative events, including cell proliferation [29]. Additionally, inflammatory cells have been shown to express substance P and NK-1R [30], which underlines our hypothesis that the increase in cell number might be explained by infiltration of inflammatory cells.

\section{Conclusions}

To conclude, there are similarities between denervated tendons and tendinosis: an increased number of cells; cells that have lost their slender spindle-shape and look disfigured; disorganized collagen architecture; an increased production of type III collagen; and an increased expression of NK-1R. As discussed above, we do not know whether the observed alterations are due to neuromuscular changes, neurotropic interactions, or immobilization alone. Nevertheless, these changes should be taken into account in order to maximize the outcome for those suffering from peripheral nerve injuries and its complications. Clinically, methods to preserve the tendon morphology and function during denervation are important for successful rehabilitation once the nerve has re-innervated the target organ.

\section{Abbreviations \\ NK-1R: Neurokinin-1 receptor; qRT-PCR: Quantitative real-time polymerase chain reaction; SP: Substance $P$}

\section{Acknowledgements}

The authors would like to thank Professor Sture Forsgren for sharing his knowledge and expertise in the field of tendinosis. The authors would also like to thank Dr. Wei Zhang for showing us how to measure the nuclear roundness using ImageJ.

\section{Funding}

Umeå University.

\section{Availability of data and materials}

The datasets used and/or analyzed during the current study are available from the corresponding author on reasonable request.

\section{Authors' contributions}

RE carried out the histological assessment, performed the statistical analysis, and drafted the manuscript. JC participated in the design of the study and helped to draft the manuscript. JP participated in the interpretation of data, and helped to critically revise the manuscript for important intellectual content. LB conceived of the study, and participated in its design and coordination. All authors read and approved the final manuscript.

\section{Ethics approval and consent to participate}

The animal care and experimental procedures were carried out in accordance with the Directive 2010/63/EU of the European Parliament and of the Council on the protection of animals used for scientific purposes. The study was also approved by the Northern Swedish Committee for Ethics in Animal Experiments (No. A186-12).

Consent for publication

Not applicable.

\section{Competing interests}

The authors declare that they have no competing interests.

\section{Publisher's Note}

Springer Nature remains neutral with regard to jurisdictional claims in published maps and institutional affiliations.

\section{Author details}

'Department of Integrative Medical Biology, Section for Anatomy, Umeå University, Johan Bures väg 12, 90187 Umeå, Sweden. ${ }^{2}$ Department of Neuroscience, University of Copenhagen, København, Denmark. ${ }^{3}$ Department of Community Medicine and Rehabilitation, Physiotherapy, Umeå University, Umeå, Sweden.

Received: 4 May 2018 Accepted: 20 November 2018

Published online: 30 November 2018

\section{References}

1. Kjaer M. Role of extracellular matrix in adaptation of tendon and skeletal muscle to mechanical loading. Physiol Rev. 2004;84(2):649-98.

2. Kannus P, Paavola M, Paakkala T, Parkkari J, Jarvinen T, Jarvinen M. Pathophysiology of overuse tendon injury. Radiologe. 2002:42(10):766-70.

3. Jozsa L, Kannus P. Histopathological findings in spontaneous tendon ruptures. Scand J Med Sci Sports. 1997;7(2):113-8.

4. Holm C, Kjaer M, Eliasson P. Achilles tendon rupture--treatment and complications: a systematic review. Scand J Med Sci Sports. 2015;25(1):e1-10.

5. Thakkar RS, Thakkar SC, Srikumaran U, McFarland EG, Fayad LM. Complications of rotator cuff surgery-the role of post-operative imaging in patient care. Br J Radiol. 2014;87(1039):20130630.

6. Ward JP, Shreve MC, Youm T, Strauss EJ. Ruptures of the distal biceps tendon. Bulletin of the Hospital for Joint Disease (2013). 2014:72(1):110-9.

7. Midrio M. The denervated muscle: facts and hypotheses. A historical review. Eur J Appl Physiol. 2006;98(1):1-21.

8. Carlson BM. The biology of long-term Denervated skeletal muscle. Eur J Transl Myol. 2014;24(1):3293.

9. Amiel D, Woo SL, Harwood FL, Akeson WH. The effect of immobilization on collagen turnover in connective tissue: a biochemical-biomechanical correlation. Acta Orthop Scand. 1982;53(3):325-32.

10. Christensen B, Dyrberg E, Aagaard P, Enehjelm S, Krogsgaard M, Kjaer M, Langberg $\mathrm{H}$. Effects of long-term immobilization and recovery on human triceps surae and collagen turnover in the Achilles tendon in patients with healing ankle fracture. J Appl Physiol (1985). 2008;105(2):420-6.

11. Christensen B, Dyrberg E, Aagaard P, Kjaer M, Langberg H. Short-term immobilization and recovery affect skeletal muscle but not collagen tissue turnover in humans. J Appl Physiol (1985). 2008;105(6):1845-51.

12. Klein L, Dawson $M H$, Heiple KG. Turnover of collagen in the adult rat after denervation. J Bone Joint Surg Am. 1977:59(8):1065-7.

13. Mannava S, Callahan MF, Trach SM, Wiggins WF, Smith BP, Koman LA, Smith TL, Tuohy CJ. Chemical denervation with botulinum neurotoxin a improves the surgical manipulation of the muscle-tendon unit: an experimental study in an animal model. J Hand Surg Am. 2011;36(2):222-31.

14. Benjamin M, Kaiser E, Milz S. Structure-function relationships in tendons: a review. J Anat. 2008;212(3):211-28.

15. Scott A, Bahr R. Neuropeptides in tendinopathy. Front Biosci (Landmark Ed). 2009:14:2203-11.

16. Ackermann PW, Li J, Lundeberg T, Kreicbergs A. Neuronal plasticity in relation to nociception and healing of rat achilles tendon. J Orthop Res. 2003;21(3):432-41.

17. Aspenberg $\mathrm{P}$, Forslund $\mathrm{C}$. Bone morphogenetic proteins and tendon repair. Scand J Med Sci Sports. 2000;10(6):372-5.

18. Shen W, Chen J, Yin Z, Chen X, Liu H, Heng BC, Chen W, Ouyang HW. Allogenous tendon stem/progenitor cells in silk scaffold for functional shoulder repair. Cell Transplant. 2012;21(5):943-58. 
19. Fenwick SA, Curry V, Harrall RL, Hazleman BL, Hackney R, Riley GP. Expression of transforming growth factor-beta isoforms and their receptors in chronic tendinosis. J Anat. 2001;199(Pt 3):231-40.

20. Gargiulo P, Reynisson PJ, Helgason B, Kern H, Mayr W, Ingvarsson P, Helgason T, Carraro U. Muscle, tendons, and bone: structural changes during denervation and FES treatment. Neurol Res. 2011;33(7):750-8.

21. Ceylan O, Seyfettinoglu F, Dulgeroglu AM, Avci A, Bayram B, Bora OA. Histomorphological comparison of immobilization and denervation atrophies. Acta Orthop Traumatol Turc. 2014;48(3):320-5.

22. Bozkurt A, Deumens R, Scheffel J, O'Dey DM, Weis J, Joosten EA, Fuhrmann T, Brook GA, Pallua N. CatWalk gait analysis in assessment of functional recovery after sciatic nerve injury. J Neurosci Methods. 2008;173(1):91-8.

23. Sharma P, Maffulli N. Biology of tendon injury: healing, modeling and remodeling. J Musculoskelet Neuronal Interact. 2006;6(2):181-90.

24. Maffulli N, Ewen SW, Waterston SW, Reaper J, Barrass V. Tenocytes from ruptured and tendinopathic achilles tendons produce greater quantities of type III collagen than tenocytes from normal achilles tendons. An in vitro model of human tendon healing. Am J Sports Med. 2000;28(4):499-505.

25. Karamichos D, Brown RA, Mudera V. Collagen stiffness regulates cellular contraction and matrix remodeling gene expression. J Biomed Mater Res A. 2007:83(3):887-94.

26. Pingel J, Lu Y, Starborg T, Fredberg U, Langberg H, Nedergaard A, Weis M, Eyre D, Kjaer M, Kadler KE. 3-D ultrastructure and collagen composition of healthy and overloaded human tendon: evidence of tenocyte and matrix buckling. J Anat. 2014;224(5):548-55.

27. Voleti PB, Buckley MR, Soslowsky LJ. Tendon healing: repair and regeneration. Annu Rev Biomed Eng. 2012;14:47-71.

28. Bring DK, Reno C, Renstrom P, Salo P, Hart DA, Ackermann PW. Joint immobilization reduces the expression of sensory neuropeptide receptors and impairs healing after tendon rupture in a rat model. J Orthop Res. 2009; 27(2):274-80.

29. Burssens P, Steyaert A, Forsyth R, van Ovost EJ, Depaepe $Y$, Verdonk R. Exogenously administered substance $P$ and neutral endopeptidase inhibitors stimulate fibroblast proliferation, angiogenesis and collagen organization during Achilles tendon healing. Foot Ankle Int. 2005;26(10):832-9.

30. Ho WZ, Lai JP, Zhu XH, Uvaydova M, Douglas SD. Human monocytes and macrophages express substance $P$ and neurokinin-1 receptor. J Immunol. 1997;159(11):5654-60.

Ready to submit your research? Choose BMC and benefit from:

- fast, convenient online submission

- thorough peer review by experienced researchers in your field

- rapid publication on acceptance

- support for research data, including large and complex data types

- gold Open Access which fosters wider collaboration and increased citations

- maximum visibility for your research: over $100 \mathrm{M}$ website views per year

At $\mathrm{BMC}$, research is always in progress.

Learn more biomedcentral.com/submissions 